\title{
Bioactive glass-based nanocomposites for personalized dental tissue regeneration
}

\author{
Jung-Hwan LEE ${ }^{1}$, Seog-Jin SEO ${ }^{1,2}$ and Hae-Won KIM'1,2,34 \\ ${ }^{1}$ Institute of Tissue Regeneration Engineering (ITREN), Dankook University, Cheonan 31116, Republic of Korea \\ ${ }^{2}$ Department of Nanobiomedical Science, Dankook University, Cheonan 31116, Republic of Korea \\ ${ }^{3}$ BK21 PLUS NBM Global Research Center for Regenerative Medicine, Dankook University, Cheonan 31116, Republic of Korea \\ ${ }^{4}$ Department of Biomaterials Science, College of Dentistry, Dankook University, Cheonan 31116, Republic of Korea \\ Corresponding author, Hae-Won KIM; E-mail: kimhw@dku.edu, Seog-Jin SEO; E-mail: seosj203@dankook.ac.kr
}

\begin{abstract}
Bioactive glass nanoparticles (BGNs) have been used over a range of dental tissue engineering. One main reason is possibly that BGNs strongly interact with hard tissues, while forming a stable interface after implantation. Recently, BGNs have been further diversified and ameliorated by incorporating bio-functional ions into BGNs or by functionally modifying the surface of BGNs. A comprehensive overview of the processes and applications of BGNs and their derivatives for the use in dentistry is thus necessary for their stepforward. Therefore, this review focuses on a variety of processes and practical applications of BGNs and their derivatives, which is expected to aid readerships with understanding and employing BGNs and their derivatives for personalized dental treatments.
\end{abstract}

Keywords: Bioactive glass, Bioactivity, Personalized dentistry, Nanocomposite, Nanoparticle

\section{INTRODUCTION}

Bioactive glasses are a group of biomaterials used in the fields of dentistry and orthopedics. In 1969, bioactive glasses were firstly introduced by Hench who implanted them in the human body ${ }^{1)}$. Those days, the implantable materials (e.g. metals and polymers) initiated fibrous encapsulation despite their bioinert property after implantation. To deal with this, Hench attempted to make a degradable silica-based glass in the $\mathrm{SiO}_{2}-\mathrm{Na}_{2} \mathrm{O}-\mathrm{CaO}$ $\mathrm{P}_{2} \mathrm{O}_{5}$ system. Silicate-based glasses composed of calcium and phosphorus similar to the component of natural bone can strongly interact with bone tissue without an intervening fibrous tissue ${ }^{1}$. Finally, he and his coworkers discovered specialized bioactive glasses composed of $46.1 \mathrm{~mol} \% \mathrm{SiO}_{2}, 24.4 \mathrm{~mol} \% \mathrm{Na}_{2} \mathrm{O}, 26.9 \mathrm{~mol} \% \mathrm{CaO}$ and $2.6 \mathrm{~mol} \% \mathrm{P}_{2} \mathrm{O}_{5}$, termed 45S5 and Bioglass ${ }^{\circledR}$, which was followed by optimizing composition of $\mathrm{SiO}_{2}$ and $\mathrm{CaO}^{2,3)}$. It was also found that bioactive glasses were chemically bound with bone and rapidly formed the hydroxyapatite (HA, $\mathrm{Ca}_{5}\left(\mathrm{PO}_{4}\right)_{3}(\mathrm{OH})$ ) layer on their surface, following initial bioactive glass degradation ${ }^{4}$. As for bioactivity, bioactive glasses are known to be biocompatible without toxicity, inflammation, and foreign-body response ${ }^{5)}$. A histological result showed good interaction of bioactive glasses with bone tissue while forming an HA layer, which can interact with collagen fibrils of damaged bone tissue ${ }^{6}$. Since then, bioactive glasses for hard tissue regeneration have been developed in medical filed. Formation of HA layer between bioactive glasses and hard tissue is well accepted to facilitate protein adsorption, attachment of progenitor cells, cell differentiation, incorporation of collagen fibrils, the

Color figures can be viewed in the online issue, which is available at J-STAGE.

Received Dec 14, 2015: Accepted Mar 30, 2016

doi:10.4012/dmj.2015-428 JOI JST.JSTAGE/dmj/2015-428 excretion of extracellular matrix and its mineralization, which is crucial for not only osteogenesis but also dentinogenesis and cementumgenesis ${ }^{7}$. Therefore, bioactive glasses and their derivatives have been highlighted for dentin, cementum or enamel regeneration in dentistry.

With the development of nanotechnology, the application of bioactive glasses has been diversified to overall application beyond hard tissue regeneration in dentistry. Nanoparticles offer more surface area to combine with other dental materials and better biological and mechanical properties for substrate materials per weight of particle, as compared with conventional microsized particles ${ }^{8}$. Along with the advantages of nanoparticles, therapeutic ions (i.e. $\mathrm{Ag}, \mathrm{Cu}, \mathrm{Sr}$ and so on) doped bioactive glass nanoparticles (BGNs) and their nanocomposites have been applied in dentistry. By virtue of above therapeutic ions released from BGNs, BGNs and their nanocomposites are able to be used as a bone or dentin substitute, which showed antibacterial, angiogenesis effects, self-healing ability or less cure shrinkage with hard tissue regenerative potential ${ }^{9-11}$. Recently, these biological effects of ions doped into BGNs and the intrinsic properties of BGNs have rendered the personalized treatment facilitated for particular patients who are susceptible of tooth caries or infection and are insufficient in regenerative potential ${ }^{12-14)}$.

Children and the elderly who have bad brushing habits and other potential patients with poor oral conditions from systemic diseases may have a lot of infection chances, such as lack of self-purification against bacteria or regenerative potential, resulting in secondary dental caries, infection of dental pulp tissues and finally tissue damage. Without additional or particular managements, it may be far from the 


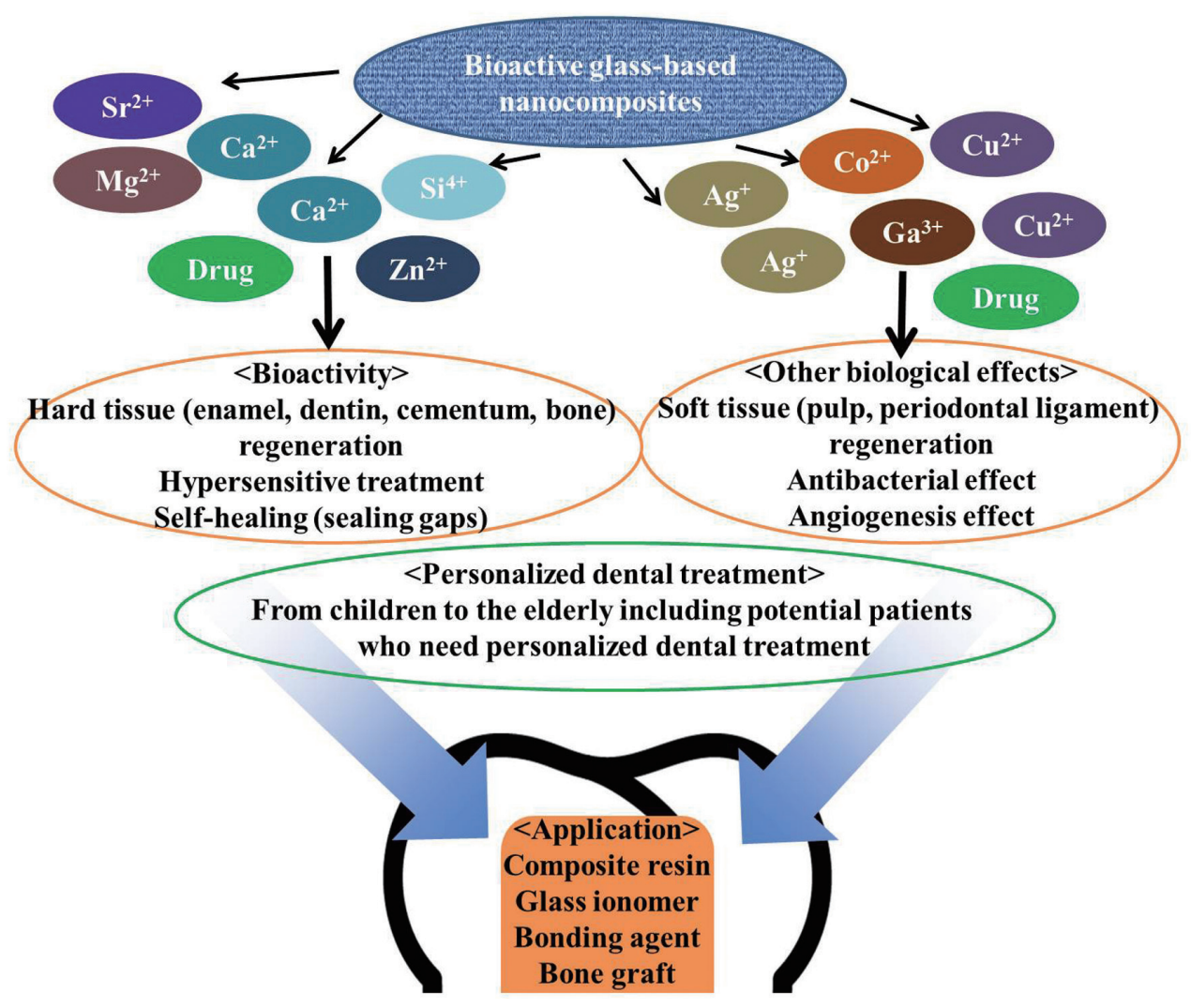

Fig. 1 Beneficial effects of therapeutic ion-doped BGNs and their nanocomposites on the personalized dental treatment.

success of tissue regeneration. Therefore, customized preparation of dental materials and the treatment of patients are imperative, which is called 'personalized dental treatment'.

Here, the usage of BGNs and their nanocomposites for dental tissue regeneration is reviewed with highlighting personalized dental treatments. Beneficial properties of bioactive glass-based nanocomposites for personalized dental treatments are depicted with representative processing methods (Fig. 1).

\section{PROCESS}

Sol-gel techniques

Advantages and disadvantages of processes for fabricating bioactive glass nanoparticles were summarized in Table 1. The sol-gel process is one of the powerful fabricating methods for synthesis of silicatebased glasses and has been widely spread due to the easy but facile preparation of $\mathrm{BGNs}^{2,15)}$. Sol-gel involves the use of metal-organic precursors which are converted to inorganic materials in either water or organic solution. The synthesis of specific silicate bioactive glasses by the sol-gel technique at low temperatures using metal alkoxides as a precursor was shown in 1991 by Li et $a l .^{2}$. Tetraethyl orthosilicate (TEOS), calcium nitrate and triethylphosphate are used as typical precursors. Gel is formed after hydrolysis and polycondensation, which subsequently is calcined at $600-700^{\circ} \mathrm{C}$ to form the bioactive glass. The morphology of bioactive glasses in terms of porosity and surface area could be tailored by varying preparations ${ }^{16)}$.

A recent work on fabricating $\mathrm{BGN}$ by sol-gel process reported by Hong et al. ${ }^{15}$ ) showed that BGNs were obtained by following two steps; sol-gel process and coprecipitation method, wherein the mixture of precursors was hydrolyzed in acidic condition and condensed in alkaline environment separately and then followed by a freeze-drying process. Mixture solution of TEOS and $\mathrm{Ca}\left(\mathrm{NO}_{3}\right)_{2}$ in ethanol and water was adjusted at $\mathrm{pH} 1-2$ with an addition of citric acid and vigorously agitated for hydrolysis. Transparent acidic mixture dropped into $\left(\mathrm{NH}_{4}\right)_{2} \mathrm{HPO}_{4}$ solution under vigorous agitation. Continuously, ammonia water was added into the solution to set the $\mathrm{pH}$ of solution to 10 11. After incubation for certain periods, formed gel and its precipitation was separated by centrifugation and freeze-dried. Finally, freeze dried gel was calcinated at $700^{\circ} \mathrm{C}$ and BGNs were gathered. The porosity, surface area, general shape and size of BGNs could be tailored by varying the production conditions and the feeding ratio of reagents ${ }^{17)}$. For example, various shapes of BGNs such 
Table 1 Advantages and disadvantages of processes for fabricating bioactive glass nanoparticles

\begin{tabular}{|c|c|c|}
\hline Process & Advantages & Disadvantages \\
\hline Sol-gel & $\begin{array}{c}\text { Simple process } \\
\text { Low cost } \\
\text { Controlled porosity, pore size and surface area } \\
\text { Homogenecity with high purity } \\
\text { Easy to add another metal precursors }\end{array}$ & $\begin{array}{l}\text { Time consuming process } \\
\text { Residual solvent leading cytotoxicity } \\
\text { High calcination temeprature } \\
\text { Relatively low production yield }\end{array}$ \\
\hline Microemulsion & $\begin{array}{l}\text { Low processing temperature } \\
\text { Minimum aggregation } \\
\text { Fast process }\end{array}$ & $\begin{array}{l}\text { Low production yield } \\
\text { Large quantity of oil and surfactant } \\
\text { High technical sensitivity }\end{array}$ \\
\hline Flame spray & $\begin{array}{c}\text { High production yield } \\
\text { No need of additional enegy } \\
\text { High chemical homogeneity } \\
\text { More bioactive due to amorphous structure }\end{array}$ & $\begin{array}{c}\text { High processing temperature } \\
\text { Limitation of metal precurosrs } \\
\text { High cost } \\
\text { Safety issue during process }\end{array}$ \\
\hline
\end{tabular}

as spherical or elliptical shapes could be fabricated ${ }^{18)}$. It is important to control the characteristics of BGNs in order to obtain the desired bioactivity or biological properties.

Lactic acid was involved in the sol-gel process of $\mathrm{CaO}-\mathrm{P}_{2} \mathrm{O}_{5}-\mathrm{SiO}_{2}$-based BGNs, which was able to control size of BGNs from 20 to $200 \mathrm{~nm}^{19)}$. With a contribution to a silane coupling agent, dispersibility of BGNs was improved and size of BGNs was changeable between 20 and $70 \mathrm{~nm}^{20)}$. Recently, different ions have been added to BGNs, such as zirconium, zinc ( $\mathrm{Zn})$, magnesium $(\mathrm{Mg})$, titanium, boron, copper $(\mathrm{Cu})$, cobalt $(\mathrm{Co})$ and silver $(\mathrm{Ag})$ in order to improve functionality and bioactivity of $\mathrm{BGNs}^{21)}$. However, it is not easy to prepare bioactive glasses in nano-size scale after addition of those ions. Delben et al. have developed sol-gel-derived silverdoped BGNs $(\sim 100 \mathrm{~nm})$ to induce antibacterial effects by releasing silver ions ${ }^{22)}$. In addition, the development of $\mathrm{BGNs}$ releasing various therapeutic ions to induce hard or nerve tissue regeneration, angiogenesis and antibacterial effects was introduced.

There was wide agreement with using a sol-gel technique to synthesize BGNs, as discussed in this section. However, the method showed limitations in terms of compositions. Moreover, remaining water or organic solvent could result in undesirable effects for the intended biomedical applications of BGNs. A high temperature calcination step made possible to eliminate organic solvent. In addition, batch-to-batch variations of BGN's characteristics may occur because of sensitivity and multiple steps of the sol-gel process.

\section{Microemulsion techniques}

The technique of microemulsion has been introduced as an appropriate method to obtain inorganic materials at the nanoscale with minimum aggregation ${ }^{23)}$. Microemulsion refers to dispersion in water, oil, and surfactant(s) that are an isotropic and thermodynamically stable system with dispersed domain diameter varying in approximate size from 10 to $50 \mathrm{~nm}$ according to IUPAC definition. In water-in-oil microemulsions, there are nanosized water droplets dispersed in the continuous hydrocarbon phase and surrounded by the monolayer of surfactant molecules ${ }^{24)}$. These aqueous droplets act as a nanoreactor in which designed reactions can take place when droplets containing the suitable reactants collide with each other. After drying and calcination of the precursor powder at an appropriate temperature, the desired ceramic particles can be obtained.

Microemulsion techniques are capable of processing nano-sized particles of organic and inorganic composition with minimal aggregation. However, low production yield despite the usage of a large amount of oil and surfactant has remained as a main disadvantage of the microemulsion techniques. Therefore, although microemulsion techniques provide an alternative way to produce nanosized inorganic and organic particles, only few reports are available on the synthesis of nano-sized bioactive glass particles using this method to prepare spherical $\mathrm{BGNs}^{25-27)}$.

\section{Flame spray synthesis (Gas phase synthesis)}

Flame spray synthesis needs metal-organic precursor compounds to produce nanoparticles above $1,000^{\circ} \mathrm{C}$. The principle of all flame spray synthesis is the formation of molecular nuclei which is followed by condensing and merging of precursor droplets, inducing the subsequent growth of nanoparticles in high temperature flame regions without requiring additional energy source ${ }^{28)}$. The most critical factor to determine the particle size is the mean residence time of particles in the high temperature regions. Short residence time $(1 \mathrm{~ms})$ with high cooling rates $(>1,000 \mathrm{~K} / \mathrm{s})$ enables the nanoparticle preparation. In contrast to above two wet phase processes, gas phase synthesis relatively gives higher production rates.

Several investigations have performed the flame spray process, which noted that key factors how they can be controlled to obtain designed nanoparticles with desired size range and chemical composition ${ }^{29,30)}$. It has 
been shown that the liquid metal carboxylate precursor is a convenient source replacing the gaseous precursor because any composition of liquid precursor could be used $^{29)}$. In this process, the liquid precursor is dispersed by oxygen gas over a nozzle thereby forming a flam spray after being ignited. As the flame spray is formed, the organic constituents of the liquid precursor completely combust, and water and carbon dioxide and metal constituents oxidize remain to form the nanoparticles.

In addition, liquid metal-carboxylate precursors are highly stable in air and humidity condition as being miscible among each other. This process allows the production of any kind of nanoparticulates with higher chemical homogeneity. Moreover fast quenching after synthesis of nanoparticles can preserve the amorphous state of the material, which is important for bioactivity of $\mathrm{BGNs}^{31,32)}$. By using flame spray synthesis, therefore, the preparation of nanoparticles of different bioactive glass compositions has made possible to use 2-ethylhexanoic acid salts of calcium and sodium, hexamethyldisiloxane, tributyl phosphate ${ }^{33,34)}$

\section{APPLICATIONS}

\section{Intrinsic properties}

Bioactive glasses have bioactivity and antibacterial effects and thus have been used as a carrier for drugs or ions ${ }^{35,36)}$. In terms of structural integrity, bioactive glasses could not be an optimal carrier due to their intrinsic brittleness ${ }^{37)}$. To achieve mechanically stable bioactive glasses, new sintering protocols including temperature and time must be optimized ${ }^{37)}$. $\mathrm{SiO}_{2}$ in the bioactive glasses is crucial for tailoring mechanical properties, bioactivity and antibacterial effects, since less than 60 wt.\% of $\mathrm{SiO}_{2}$ could be bioactive but more could be biologically inert ${ }^{38)}$. Increase in $\mathrm{SiO}_{2}$ is able to increase in their mechanical properties such as hardness, compressive strength. Therefore, increase in $\mathrm{SiO}_{2}$ was suggested to increase in the surface area to higher percentages while maintaining bioactivity and improving mechanical properties ${ }^{39)}$.

Addition of positively charged ions, such as $\mathrm{Zn}^{2+}$, $\mathrm{Cu}^{2+}, \mathrm{Ag}^{+}, \mathrm{Al}^{3+}, \mathrm{Ti}^{4+}$ or $\mathrm{Ta}^{5+}$, to the bioactive glass has been performed to control intrinsic properties of bioactive glass ${ }^{40)}$. For instance, metal ions can render mechanical properties of bioactive glasses sustained or decreased ${ }^{41}$. Therefore, one main reason of addition of these ions to bioactive glasses may make possible to modulated bioactivity and other biological effects. In another example, $\mathrm{Ca}^{2+}$ and $\mathrm{Si}^{4+}$ released from implanted bioactive glasses can be a precursor of HA and increase in $\mathrm{pH}$, inducing antibacterial effects. Released $\mathrm{Mg}, \mathrm{Sr}, \mathrm{Cu}$, $\mathrm{Co}, \mathrm{Ag}$ and $\mathrm{Ga}$ ions as metal precursors from bioactive glasses could facilitate odontogenesis, osteogenesis, angiogenesis and antibacterial effect ${ }^{21)}$.

Applicable forms of bioactive glasses in dentistry can be diversified to particles, porous scaffolds, or dense constructs. Dentists prefer to use a form of particles or granules rather than a bulk style, as they can be easily pressed to fill a defect. In 1993, Perio-Glas ${ }^{\circledR}$ (NovaBone
Products, Alachua, FL, USA) was introduced as the first particulate bioactive glass with the size range of 90-710 $\mu \mathrm{m}$ for the repair of bony defects of the jaw and bone loss by periodontal disease. Other bioactive glass products, which have been used as a grafting material in dentistry, include Biogran $^{\circledR}$ (BIOMET 3i, Palm Beach Gardens, FL, USA) and BonAlive ${ }^{\circledR}$ (BonAlive Biomaterials, Turku, Finland) ${ }^{35,42)}$. In vivo and clinical studies showed a success of bone synthesis with PerioGlas $^{\circledR}$ compared to controls. Perio-Glas ${ }^{\circledR}$ has been used in "guided tissue regeneration" as a polymer membrane as well as sterilizing material for root canal therapy prior to inserting dental implants, raising $\mathrm{pH}$ to bactericidal levels in addition to its bioactive properties ${ }^{43-47)}$.

BGNs have gained attention due to their promising bioactivity and nanosize effects. They have larger surface area to release ions than microsized bioactive glass particles. By controlling the particle size to nanoscale, properties like osteoconductive, dissolution, drug loading capacity and other vital characteristics can be greatly improved. The nanostructured surface enhances cell adhesion, enhances proliferation, promotes differentiation, and increases bioactivity (biomineralization) $^{48)}$. It was also reported that they have different intrinsic characteristics depending on the shape (i.e. wire, fiber and tube).

Also BGNs with mesoporosity have been developed to efficiently deliver biological molecules such as siRNA, growth factors and therapeutic drugs due to their ability of endocytosis and biocompatibility ${ }^{49)}$. Pore diameter of mesoporous BGNs usually ranges between 2 and $50 \mathrm{~nm}$ according to IUPAC notation compared to microporous and macroporous materials with diameters of less than $2 \mathrm{~nm}$ and greater than $50 \mathrm{~nm}$ respectively ${ }^{4,50)}$. As an approach to locally deliver the drugs in implanted site ${ }^{51)}$ mesoprous BGNs have shown high delivery efficiency, continuous action, biocompatibility and bioactivity due to higher surface areas and larger pore volumes than conventional bioactive glasses ${ }^{52-54)}$. Therefore, BGNs are able to be employed as a graft materials replacing dentin and cementum or for jaw and alveolar bone in periodontology and endodontology ${ }^{55,56)}$.

Beneficial effects of bioactive glass nanocomposites on dental hard tissues

BGNs have an advantage as for superior apatitemineralization ability in biological solution, expecting excellent hard tissue regeneration. In the past, many studies focused on the in vitro bioactivity of BGNs with different forms, including particles and composite scaffolds. Yan et al. found that apatite mineralization of BGNs was formed only after incubation with SBF for $4 \mathrm{~h}^{57)}$. In particular, apatite mineralization of nano-sized particles superior to that of other-sized particles, due possibly to the highly specific surface area of nanoparticles, enhancing ion releasing and bioactive behavior ${ }^{57)}$. According to the nuclear magnetic resonance spectroscopy study regarding mechanism of apatite mineralization of BGNs, conventional bioactive glass particles require typical 'first three stages' but 
BGNs do not ${ }^{7,58)}$. In the first three stages, conventional bioactive glass particles release silicate ions and form $\mathrm{Si}-\mathrm{OH}$ groups, and then $\mathrm{Si}-\mathrm{OH}$ groups form networks by repolymerization. By contrast, the surface of BGNs is inherently able to accelerate these first three stage ${ }^{58)}$. These findings indicate that BGNs and their composites are appropriate to hard tissue engineering.

In 1988, a simple cone of Bioglass ${ }^{\circledR}$, termed the Endosseous Ridge Maintenance Implant (ERMI ${ }^{\circledR}$ ), was commercially available in dentistry. To repair the tooth roots and to provide a stable alveolar bone ridge for dentures and dental implants, such micro-sized bioactive glasses were inserted into fresh tooth extraction or bony defects area. They showed high stability and much better efficacy than that of HA-based hard tissue substitutes. However, they failed to gain a commercial attention, since dental surgeons preferred the customized graft rather than the ready-made one.

In tooth extraction sites, BGNs have been used not only to preserve the height of the alveolar ridge ${ }^{59}$ but also to reconstruct the mandible or maxilla bone following autograft harvesting, and to fill bony defects as well. These clinical applications confirmed the benefits of BGNs as a highly compatible graft in dentistry ${ }^{60)}$. More recent applications of BGNs include several exemplar studies on doping therapeutic ions for accelerating hard tissue regeneration or coatings of hard tissue substitute with these nanocomposites ${ }^{55,61)}$.

$\mathrm{Mg}$ or $\mathrm{Sr}$ is an important trace element in human bone. $\mathrm{Mg}$ ions play a critical role in bone remodeling and skeletal tissue development and for nucleation in biological apatites ${ }^{62)}$. $\mathrm{Sr}^{2+}$ ions are able to impact bonerelated cells and induce osteoblast activity by stimulating bone formation and reducing bone resorption ${ }^{63)}$. For this reason, $\mathrm{Mg}$ and $\mathrm{Sr}$ have been incorporated into biomaterials to further improve their bioactivity for bone-regeneration applications ${ }^{64,65)}$. They can be substituted instead of calcium in BGNs for better bone remodeling and osseosysthesis stimulation and iondoped BGNs promoted osteoblast proliferation while also decreasing in the osteoclast activity ${ }^{66,67)}$.

Scaffolds are still needed in dentistry for oral environment regeneration. For hard tissue regeneration in dentistry, there has been widespread use of bioceramic scaffolds, such as HA, tri-calcium phosphate and those composites. However, their clinical applications have been limited because of their brittleness, difficulty of shaping, and absence of other functionality ${ }^{68)}$. Therefore, BGN-added nanocomposite bioceramic scaffold was introduced to overcome above the drawbacks. In addition, numerous synthetic polymers including polycaprolactone, polyethylene glycol (PEG), poly-l-lactic acid (PLLA), polyglycolic acid (PGA) and poly-dl-lactic-co-glycolic acid (PLGA) with nanocomposites have been used in the attempt to produce scaffolds in dentistry. Because these materials can be fabricated with a tailored architecture, their degradable characteristics can be controllable and replaced by host hard tissue ${ }^{69,70)}$. Without BGNs, the synthetic polymer itself has drawbacks due to reduced bioactivity, low mechanical properties and lowering the local $\mathrm{pH}$ due to byproducts after hydrolysis ${ }^{71}$. Therefore, various BGNs have been fabricated with bioceramic cement and synthetic polymers for osteogenic or odontogenic properties ${ }^{12-14,72,73)}$. Owing to mesoporosity of BGNs, therapeutic drugs could be loaded and accelerate biological effects of these nanocompositebased $\mathrm{BGNs}^{49,74-77)}$.

Use of BGNs for treatment of hypersensitivity in the tooth restoration has led to a form of very fine Bioglass ${ }^{\circledR}$ particulates called NovaMin ${ }^{\circledR}$ (NovaMin Technology, GlaxoSmithKline, London, UK) and sol-gel derived BGNs as an active repair additive in toothpaste. This material makes tiny holes in the dentine filled with minerals so as to reduce sensitivity of the tooth. Dentin hypersensitivity is caused by dentin exposure in root surface due to periodontal disease, toothbrush abrasion or cyclic loading fatigue of the thin enamel near the cemento-enamel junction ${ }^{78)}$. The hydrodynamic theory about dentin hypersensitivity mechanisms explains how BGNs reduce hypersensitivity. When external stimuli such as contact to cold or hot materials, and osmotic pressure are applied to the exposed dentin, they cause fluid movement within the open-dentinal tubules, which may result in pressure changes in the dental pulp nerve endings ${ }^{78}$. When BGN-included toothpastes are used, BGNs adhere to the open-dentinal tube and form an apatite-like layer; therefore, blocking the dentinal tubules halts pressure changes in the dental pulp nerve endings and relieves the pain for longer periods. An in vitro study, showed a good attachment of BGNs to the lightly etched human dentin and an apatite-like layer was covered with the surface within $24 \mathrm{~h}$. This showed that BGNs stimulated the deposition of calcium phosphate over the dentine tubules via bioactivity ${ }^{53)}$. In a clinical trial, volunteers who brushed with a NovaMin ${ }^{\circledR}$ containing toothpaste over 2-6 weeks experienced pain relief compared to users of a normal toothpaste as a control group.

However, periodontal tissue regeneration still remains a big challenge in periodontics, mainly when large defects are concerned. Guided tissue regeneration is by far the best studies in the dental filed and has contributed to regeneration ${ }^{79)}$. In this regard, BGNs have been considered promising for regenerative applications including cementoblast compatability, cementum regeneration, filling of bone defects, the reduction of probing depth and clinical attachment gain ${ }^{80-83)}$. Incorporation of Sr into BGNs accelerated the biological response to periodontal ligament cells due to releasing effects of $\mathrm{Sr}^{2+}$ ions ${ }^{79)}$. Therefore, combination of ion doped BGNs with guided tissue regeneration technique seems like to be applied in periodontal tissue regeneration.

\section{Other applications in dentistry}

Antibacterial effect of BGNs has been used in dentistry. During dissolution of BGNs, $\mathrm{pH}$ rises up by various released cations and such high $\mathrm{pH}$ condition can kill microbes ${ }^{1)}$. For instance, an in vitro study showed that $\mathrm{S} 53 \mathrm{P} 4 \mathrm{BGNs}$ can kill pathogens attached to enamel caries 
(Streptococcus mutans), root caries (e.g. Enterococcus faecalis, Actinomyces naeslundii and Streptococcus mutans) and periodontitis (e.g. Actinobacillus actinomycetemcomitas and Pseudomonas aeruginosa) ${ }^{84)}$. Also S53P4 BGNs and other nanocomposite-based BGNs with higher than $50 \mathrm{mg} / \mathrm{mL}$ in the broth cultures of 16 different bacteria showed antibacterial properties due to the high $\mathrm{pH}^{84)}$. It is evidenced that ideal BGNs include antibacterial elements which prevent infections. The possible elements for this purpose are antibacterial metal ions ${ }^{20)}$. Ag is one of representative elements known as antimicrobial, which is induced by destruction of essential enzymes for homeostasis of bacteria, inhibition of cell division and interaction with nucleic acids ${ }^{85)}$. Ag precursors can be easily introduced into BGNs and then $\mathrm{Ag}$ ions can be released during their dissolution. The sol-gel derived BGN composition of $76 \% \mathrm{SiO}_{2}, 19 \% \mathrm{CaO}$, $3 \% \mathrm{Ag}_{2} \mathrm{O}$ and $2 \% \mathrm{P}_{2} \mathrm{O}_{5}$ (by weight) affected antibacterial treatments, particularly due to $\mathrm{Ag}$ ions ${ }^{22}$. Less than $1 \mathrm{mg} /$ $\mathrm{mL}$ is enough to kill oral pathogens such as Escherichia coli, Pseudomonas aeruginosa and Staphylococcus aureus while $50 \mathrm{mg} / \mathrm{mL}$ of silver-free glasses is needed to be bactericidal. It is promising that low concentrations of the sol-gel derived BGNs that can be bactericidal were not cytotoxic to human osteoblasts ${ }^{86)}$. Cu, Co Ni, and its alloys can also be used in antimicrobial precursor for $\mathrm{BGNs}^{87,88)}$.

In addition, other biological effects are gaining attention for adding functional ions to BGNs. For example, $\mathrm{Cu}$, an excellent antimicrobial agent, plays an essential role in forming bone tissue, triggering wound healing, and improving angiogenesis with elastin matrix deposition around implanted sites ${ }^{89-91)}$. Previous studies suggested that insufficient level of oxygen, a condition known as hypoxia, plays a critical role in endothelial recruitment, differentiation and blood vessel formation, linking to angiogenesis. Hypoxia can be artificially induced by treating $\mathrm{Cu}$ ions and, consequently, $\mathrm{Cu}$ can induce angiogenesis further by replacing the calcium element $^{92)}$.

Zn also improves bone bonding with BGNs, inhibits bone resorption, controls osteoblastic cell growth, differentiation, and development, and stimulates apatite formation $^{93)}$. $\mathrm{Zn}$ acts as nucleation for apatite formation and accelerates biological activities of osteoblast cells associated with $\mathrm{BGNs}^{94)}$. In addition, $\mathrm{Zn}$, another metal precursor in bioactive glass, is thought to have antibacterial properties, but it can cause cytotoxicity in higher concentrations ${ }^{95)}$. Ga has diverse therapeutic activities such as suppressing osteoclast activity, immunomodulating activities, and antibacterial effects. Mechanisms for Ga's antimicrobial activity is likely to similarities of $\mathrm{Ga}$ and $\mathrm{Fe}$ ions in a view of bacteria. Ga ions enter microbes through Fe ion transport, disrupt Fe metabolism and interfere with DNA and protein synthesis $^{96,97)}$.

Modification of dental adhesive or glass ionomer cement with therapeutic ions doped into BGNs is one of the most attractive approaches in future dentistry. Microleakage of dental materials is one of the representative reasons for failure of restoration with functional dental materials, which released therapeutic drugs or biomolecules leading to vacancy in restorative material. With BGNs-added dental materials, gaps could be healed due to self-sealing properties of bioactive behavior of BGNs, which decrease gap-oriented secondary caries and micropenetration of oral bacteria. Along with the self-sealing effects, other functionalities, such as antibacterial effect and angiogenesis, from doped therapeutic ions are able to prevent the failure of hard tissue restorations in oral cavity by killing oral bacteria and increasing blood supply. Biological and mechanical characteristics of ion doped BGNs have been investigated so far, applications in currently used dental materials (i.e. dental adhesive and restorative material) have been less tried, which is needed further.

Biocompatibility of bioactive glass-based nanocomposites Bioactive glass has been considered as one of the outstanding biocompatible materials, and the use of their nanocomposites has been suggested as a promising strategy to enhance cell-biomaterial interaction. Currently, there exist many types of bioactive glasses approved by Food and Drug Administration (FDA) in the market and termed 'Bioactive glass', which reveals biocompatibility of bioactive glass particles. However, their nanoparticulate forms still include safety issues due to the concern of toxicity attributed to high reactivity and easy endocytic property ${ }^{98)}$. According to the revealed results, cytotoxicity could be dependent on the cell type and the ratio of cell number to nanoparticle concentration. Toxicity of BGNs in dental tissue-derived cells such as dental pulp stem cells, odontoblasts, periodontal ligament cells, cementoblasts and gingival fibroblasts was not detected in the low concentration $(\leq 100 \mu \mathrm{g} / \mathrm{mL})$ and the in vivo study ${ }^{99-102)}$ including several clinical cases ${ }^{5,13,69,74)}$. However, further detailed researches of BGNs including the long-term study are needed for their safe use $\mathrm{u}^{9,13,14)}$.

\section{Personalized dental treatment using ion-doped BGNs}

Personalized treatments performed on the basis of CAD/CAM process have been suited for each dental patient, which fabricates customized restorative tooth structure $^{103)}$. Despite their promise, there have been limits on dental materials and technologies used for personalized dental treatment, which could not deal with oral poor condition or infection in certain types of patients ${ }^{104)}$. This infection could be due to poor dental treatment procedures or patients' particular conditions ${ }^{105)}$. Poor oral conditions can induce dental tissue degeneration. This could be initiated by bad brushing habits or invasion of germs by external injury. Especially, the symptoms of the elderly who have relatively less amounts of saliva secretion and less angiogenesis potential could be severe than the young.

In this respect, BGNs or therapeutic ion-doped BGNs have been suggested as an emerging implant for the personalized dental treatment ${ }^{106)}$. For instance, they can be suitable for the patients suffering from 
Table 2 Functional property from therapeutic ions of BGNs and personalized dental treatment

\begin{tabular}{|c|c|c|}
\hline $\begin{array}{l}\text { Therapeutic ions released } \\
\text { from BGNs }\end{array}$ & $\begin{array}{l}\text { Functional } \\
\text { property }\end{array}$ & Personalized dental treatment \\
\hline $\begin{array}{l}\mathrm{Sr}^{2+} \\
\mathrm{Mg}^{2+} \\
\mathrm{Fe}^{2+} \\
\mathrm{B}^{3+} \\
\mathrm{Zn}^{2+} \\
\mathrm{Li}^{+} \\
\mathrm{Zr}^{4+}\end{array}$ & $\begin{array}{l}\text { Hard tissue } \\
\text { regeneration }\end{array}$ & $\begin{array}{l}\text { People lack of hard tissue regenerative potential } \\
\text { (dental pulp tissue, bone, cementum) }\end{array}$ \\
\hline $\begin{array}{l}\mathrm{Ag}^{+} \\
\mathrm{Cu}^{2+} \\
\mathrm{Co}^{2+} \\
\mathrm{Ga}^{3+}\end{array}$ & $\begin{array}{l}\text { Antibacterial } \\
\text { acitivity }\end{array}$ & $\begin{array}{l}\text { Children and the elderly who have bad brushing habits } \\
\text { Other potential patients who have poor oral conditions } \\
\text { from systemic diseases }\end{array}$ \\
\hline $\begin{array}{l}\mathrm{Cu}^{2+} \\
\mathrm{Co}^{2+}\end{array}$ & Angiogenesis & $\begin{array}{l}\text { Children who need blood supply for further tooth development } \\
\text { The elderly who need blood supply for proper regeneration }\end{array}$ \\
\hline
\end{tabular}

hypersensitivity, which requires dentin tissue formation for blocking dentinal tube ${ }^{33,53)}$, since they are able to be controllably prepared and treated. Functional property from therapeutic ions from BGNs or BGNs-based nanocomposite and its personalized dental treatment were summarized in Table 2.

$\mathrm{Sr}, \mathrm{Mg}, \mathrm{Fe}, \mathrm{B}, \mathrm{Zn} \mathrm{Li}$ or $\mathrm{Zr}$ ions are well known for accelerating hard tissue regeneration and these iondoped BGNs and nanocomposites could be used for the special dental patient deficient in tissue regeneration force. The in vitro studies using B ion-doped implants showed no cytotoxic effects in bone-marrow mesenchymal stem cells, and ions were gradually released into the culture medium, resulting in enhanced cell proliferation and alkaline phosphatase (ALP) activity and mineralization ${ }^{107)}$. Sr, Fe, Mg, Zn or Zr-doped BGNs and their nanocomposite enhanced cell proliferative activity and apatite formation ability as well as the expression of bone-related genes (osteocalcin and ALP) and dentin-related genes (DSPP and DMP) in human bone-marrow mesenchymal stem cells and pulp stem cells ${ }^{108,109)}$. Li-doped BGNs and their nanocomposites in the use of human periodontal ligament-derived cells improved cementum formation of the cells and thereby mineralization during periodontal regeneration, which is responsible for linking the roots and surrounding alveolar bone ${ }^{110)}$.

In addition to studies of specific effects of BGNs in hard regeneration, several reports have focused on the antibacterial properties, resulting from release of antibacterial ions in surrounding area, for the treatment or prevention of infections in dental pulp or periodontal tissues. $\mathrm{Ag}, \mathrm{Cu}, \mathrm{Co}$ and $\mathrm{Ga}$ ions are known to induce antibacterial effects like a broad spectrum of antibiotics, and these ion-doped BGNs and nanocomposites could be used for patients having periodontal diseases infected by bacteria in the treatment area. For example, Ag-doped BGNs and their nanocomposites can be used for not only bacteriostatic but also bactericidal materials against Streptococcus mutans, Staphylococcus aureus and E. coli growth which are responsible for dental tissue infection and dental careis ${ }^{55,111,112)}$. These antibacterial properties are likely due to leaching of silver ions which interfere with several cellular mechanisms and induce dysfunction in a not yet fully understood way ${ }^{113)}$. By virtue of silver ion release, antibacterial effects in the treatment site were positive in terms of tissue regeneration.

$\mathrm{Cu}$ and $\mathrm{Co}$ ions have shown a promising potential of angiogenesis, and these ion-doped BGNs and nanocomposites could be used for children and the elderly who need blood supply for further tooth development and proper regeneration respectively. Recently, Co-dooped BGNs and their nanocomposites induced a hypoxic environment for enhancing angiogenesis, as estimated by confirming the expression of hypoxia-inducible factor- $1 \alpha$ as well as dentin-related gene expression of dental pulp stem cells ${ }^{56,114)}$. Similar results can be achieved by incorporating $\mathrm{Cu}$ in BGNs and their nanocomposites ${ }^{92,115)}$. Above angiogenesis potential BGNs-based nanocomposites can be applied for the elderly or genetically modified patients who need an increase in blood supply, or children who need angiogenesis for root formation.

\section{CONCLUSION}

A comprehensive overview of the processes and applications of BGNs and their derivatives for the use in dentistry was presented in this article. BGNs can be produced via three methods, sol-gel processing, microemulsion techniques and flame spray synthesis method. Among these techniques, sol-gel processing has been widely used to make BGNs due to their simple operation, low cost and controllable properties of BGNs. Taking into account beneficial effects of BGNs on binding to oral hard tissue and promoting the hard 
tissue growth, BGNs and their derivatives have been customized for the purpose of hard tissue regeneration as well as hypersensitivity treatments. BGNs have been further beneficial for hard tissue regeneration by incorporating variable doping materials, which can show improvement of dentin, cementum and bone regeneration in pulp or periodontal tissue. These beneficial effects include an antibacterial or angiogenesis activity, which creates a bacteria-free environment in implanted sites while healing and regenerating the soft or hard tissue with enough blood supply. The addition of therapeutic elements, such as $\mathrm{Ag}, \mathrm{Cu}, \mathrm{Co}, \mathrm{Zn}$ or $\mathrm{Ga}$ precursors to BGNs have shown more promoted therapeutic effects than when using primitive BGNs, and it is possible to use for personalized dental treatments. However, there remains further detailed research e.g., of long-term study fur their safe use in the clinical application.

\section{CONFLICTS OF INTEREST}

The author has no financial relationship with the organization that sponsored this research.

\section{ACKNOWLEDGMENTS}

This research was supported by Basic Science Research Program through the National Research Foundation of Korea (NRF) funded by the Ministry of Science, ICT \& Future Planning (NRF-2015R1C1A1A01052127) and Research Fellowship Program (NRF2013R1A1A2062694) funded by the NRF of Korea.

\section{REFERENCES}

1) Hench LL. The story of bioglass. J Mater Sci Mater Med 2006; 17: 967-978.

2) Li R, Clark AE, Hench LL. An investigation of bioactive glass powders by sol-gel processing. J Appl Biomater 1991; 2: 231239.

3) Laudisio G, Branda F. Sol-gel synthesis and crystallisation of $3 \mathrm{CaO} \cdot 2 \mathrm{SiO}_{2}$ glassy powders. Thermochim Acta $2001 ; 370$ : 119-124.

4) Hench LL, Splinter RJ, Allen WC, Greenlee TK. Bonding mechanisms at the interface of ceramic prosthetic materials. J Biomed Mater Res 1971; 5: 117-141.

5) Jo JH, Lee EJ, Shin DS, Kim HE, Kim HW, Koh YH, Jang JH. In vitro/in vivo biocompatibility and mechanical properties of bioactive glass nanofiber and poly ( $\varepsilon$-caprolactone) composite materials. J Biomed Mater Res B Appl Biomater 2009; 91: 213-220.

6) Hench LL, Paschall H. Direct chemical bond of bioactive glass-ceramic materials to bone and muscle. J Biomed Mater Res 1973; 7: 25-42.

7) Hench LL, Polak JM. Third-generation biomedical materials. Science 2002; 295: 1014-1017.

8) Kumar SR, Vijayalakshmi R. Nanotechnology in dentistry. Indian J Dent Res 2006; 17: 62-65.

9) Chen MH. Update on dental nanocomposites. J Dent Res 2010; 89: 549-560.

10) Khurshid Z, Zafar M, Qasim S, Shahab S, Naseem M, AbuReqaiba A. Advances in nanotechnology for restorative Dentistry. Materials (Basel) 2015; 8: 717.

11) Padovani GC, Feitosa VP, Sauro S, Tay FR, Durán G, Paula AJ, Durán N. Advances in dental materials through nanotechnology: Facts, perspectives and toxicological aspects. Trends Biotechnol 33; 11: 621-636.

12) Zhang J, Park YD, Bae WJ, El-Fiqi A, Shin SH, Lee EJ, Kim HW, Kim EC. Effects of bioactive cements incorporating zinc-bioglass nanoparticles on odontogenic and angiogenic potential of human dental pulp cells. J Biomater Appl 2015; 29: 954-964.

13) ElFiqi A, Kim JH, Perez RA, Kim HW. Novel bioactive nanocomposite cement formulations with potential properties: incorporation of the nanoparticle form of mesoporous bioactive glass into calcium phosphate cements. J Mater Chem B Mater Biol Med 2015; 3: 1321-1334.

14) Kim GH, Park YD, Lee SY, El-Fiqi A, Kim JJ, Lee EJ, Kim HW, Kim EC. Odontogenic stimulation of human dental pulp cells with bioactive nanocomposite fiber. J Biomater Appl 2015; 29: 854-866.

15) Hong Z, Reis RL, Mano JF. Preparation and in vitro characterization of novel bioactive glass ceramic nanoparticles. J Biomed Mater Res A 2009; 88: 304-313.

16) Scherrer GW, CJ B. Sol-Gel science: the physics, chemistry of sol-gel. Boston (MA): Academic Press; 1990.

17) Hong Z, Merino EG, Reis RL, Mano JF. Novel rice-shaped bioactive ceramic nanoparticles. Adv Eng Mater 2009; 11: B25-B29.

18) Couto DS, Hong Z, Mano JF. Development of bioactive and biodegradable chitosan-based injectable systems containing bioactive glass nanoparticles. Acta Biomater 2009; 5: 115123.

19) Chen $X$, Lei B, Wang $Y$, Zhao N. Morphological control and in vitro bioactivity of nanoscale bioactive glasses. J Non Cryst Solids 2009; 355: 791-796.

20) Chen X, Guo C, Zhao N. Preparation and characterization of the sol-gel nano-bioactive glasses modified by the coupling agent gamma-aminopropyltriethoxysilane. Appl Surf Sci 2008; 255: 466-468.

21) Bose S, Fielding G, Tarafder S, Bandyopadhyay A. Understanding of dopant-induced osteogenesis and angiogenesis in calcium phosphate ceramics. Trends Biotechnol 2013; 31: 594-605.

22) Delben JRJ, Pimentel OM, Coelho MB, Candelorio PD, Furini LN, dos Santos FA, de Vicente FS, Delben AA. Synthesis and thermal properties of nanoparticles of bioactive glasses containing silver. J Therm Anal Calorim 2009; 97: 433-436.

23) Pileni M-P. The role of soft colloidal templates in controlling the size and shape of inorganic nanocrystals. Nat Mater 2003; 2: $145-150$

24) Arriagada FJ, Osseo-Asare K. Synthesis of nanosize silica in a nonionic water-in-oil microemulsion: Effects of the water/ surfactant molar ratio and ammonia concentration. J Colloid Interface Sci 1999; 211: 210-220.

25) Lim GK, Wang J, Ng SC, Gan LM. Processing of fine hydroxyapatite powders via an inverse microemulsion route. Mater Lett 1996; 28: 431-436.

26) Bose S, Saha SK. Synthesis and characterization of hydroxyapatite nanopowders by emulsion technique. Chem Mater 2003; 15: 4464-4469.

27) Wang $\mathrm{H}$, Chen $\mathrm{X}$, Wang $\mathrm{Y}$, Cheng D. Preparation and characterization of the system $\mathrm{SiO}_{2}-\mathrm{CaO}-\mathrm{P}_{2} \mathrm{O}_{5}$ bioactive glasses by microemulsion approach. J Wuhan Univ Technol Mater Sci Ed 2013; 28: 1053-1057.

28) Stark WJ, Mädler L, Maciejewski M, Pratsinis SE, Baiker A. Flame synthesis of nanocrystalline ceria-zirconia: effect of carrier liquid. Chem Commun (Camb) 2003: 588-589.

29) Laine RM, Bickmore CR, Treadwell DR, Waldner KF. Ultrafine metal oxide powders by flame spray pyrolysis. Google Patents; 1999.

30) Athanassiou EK, Grass RN, Stark WJ. Chemical aerosol engineering as a novel tool for material science: From oxides to salt and metal nanoparticles. Aerosol Sci Technol 2010; 44: 
161-172.

31) Brunner TJ, Grass RN, Stark WJ. Glass and bioglass nanopowders by flame synthesis. Chem Commun (Camb) 2006: 1384-1386.

32) Loher S, Stark WJ, Maciejewski M, Baiker A, Pratsinis SE, Reichardt D, Maspero F, Krumeich F, Günther D. Fluoroapatite and calcium phosphate nanoparticles by flame synthesis. Chem Mater 2005; 17: 36-42.

33) Vollenweider M, Brunner TJ, Knecht S, Grass RN, Zehnder M, Imfeld T, Stark WJ. Remineralization of human dentin using ultrafine bioactive glass particles. Acta Biomater 2007; 3: 936-943

34) Mohn D, Zehnder M, Imfeld T, Stark WJ. Radio-opaque nanosized bioactive glass for potential root canal application: evaluation of radiopacity, bioactivity and alkaline capacity. Int Endod J 2010; 43: 210-217.

35) Jones JR. Review of bioactive glass: From Hench to hybrids. Acta Biomater 2013; 9: 4457-4486.

36) Plewinski M, Schickle K, Lindner M, Kirsten A, Weber M, Fischer $\mathrm{H}$. The effect of crystallization of bioactive bioglass $45 \mathrm{~S} 5$ on apatite formation and degradation. Dent Mater 2013; 29: 1256-1264.

37) Chen QZ, Thompson ID, Boccaccini AR. 45S5 Bioglass ${ }^{\circledR}$ derived glass-ceramic scaffolds for bone tissue engineering. Biomaterials 2006; 27: 2414-2425.

38) Greenspan DC, Hench LL. Chemical and mechanical behavior of bioglass-coated alumina. J Biomed Mater Res 1976; 10: 503-509.

39) Jones JR, Gentleman E, Polak J. Bioactive glass scaffolds for bone regeneration. Elements 2007; 3: 393-399.

40) Bejarano J, Caviedes P, Palza H. Sol-gel synthesis and in vitro bioactivity of copper and zinc-doped silicate bioactive glasses and glass-ceramics. Biomed Mater 2015; 10: 025001.

41) Kokubo T, Kim HM, Kawashita M. Novel bioactive materials with different mechanical properties. Biomaterials 2003; 24: 2161-2175

42) Turunen T, Peltola J, Yli-Urpo A, Happonen RP. Bioactive glass granules as a bone adjunctive material in maxillary sinus floor augmentation. Clin Oral Implants Res 2004; 15: 135-141.

43) Wilson J, Low SB. Bioactive ceramics for periodontal treatment: comparative studies in the Patus monkey. J Appl Biomater 1992; 3: 123-129.

44) Park JS, Suh JJ, Choi SH, Moon IS, Cho KS, Kim CK, Chai JK. Effects of pretreatment clinical parameters on bioactive glass implantation in intrabony periodontal defects. $J$ Periodontol 2001; 72: 730-740.

45) Norton MR, Wilson J. Dental implants placed in extraction sites implanted with bioactive glass: human histology and clinical outcome. Int J Oral Maxillofac Implants 2002; 17: 249-257.

46) Yadav VS, Narula SC, Sharma RK, Tewari S, Yadav R. Clinical evaluation of guided tissue regeneration combined with autogenous bone or autogenous bone mixed with bioactive glass in intrabony defects. J Oral Sci 2011; 53: 481488.

47) Waltimo T, Mohn D, Paque F, Brunner TJ, Stark WJ, Imfeld T, Schatzle M, Zehnder M. Fine-tuning of bioactive glass for root canal disinfection. J Dent Res 2009; 88: 235-238.

48) Ajita J, Saravanan S, Selvamurugan N. Effect of size of bioactive glass nanoparticles on mesenchymal stem cell proliferation for dental and orthopedic applications. Mater Sci Eng C 2015; 53: 142-149.

49) Kang MS, Kim JH, Singh RK, Jang JH, Kim HW. Therapeuticdesigned electrospun bone scaffolds: mesoporous bioactive nanocarriers in hollow fiber composites to sequentially deliver dual growth factors. Acta Biomater 2015; 16: 103-116.

50) Wu C, Chang J. Mesoporous bioactive glasses: structure characteristics, drug/growth factor delivery and bone regeneration application. Interface Focus 2012: rsfs20110121.

51) Pradeep AR, Sharma A. Comparison of clinical efficacy of a dentifrice containing calcium sodium phosphosilicate to a dentifrice containing potassium nitrate and to a placebo on dentinal hypersensitivity: a randomized clinical trial. J Periodontol 2010; 81: 1167-1173.

52) Tai BJ, Bian Z, Jiang H, Greenspan DC, Zhong J, Clark $\mathrm{AE}, \mathrm{Du} \mathrm{MQ}$. Anti-gingivitis effect of a dentifrice containing bioactive glass $\left(\right.$ NovaMin $\left.^{\circledR}\right)$ particulate. J Clin Periodontol 2006; 33: 86-91.

53) Earl J, Leary R, Muller K, Langford R, Greenspan D. Physical and chemical characterization of dentin surface following treatment with NovaMin technology. J Clin Dent 2010; 22: 62-67.

54) Patel ED, Verma S, Raghu T. Anti-gingivitis effect of a dentifrice containing bioactive glass particulate a clinical and microbiological study. Int J Dent Clin 2012; 4.

55) Boccaccini AR, Erol M, Stark WJ, Mohn D, Hong Z, Mano JF. Polymer/bioactive glass nanocomposites for biomedical applications: a review. Compos Sci Technol 2010; 70: 17641776.

56) Polini A, Bai H, Tomsia AP. Dental applications of nanostructured bioactive glass and its composites. Wiley Interdiscip Rev Nanomed Nanobiotechnol 2013; 5: 399-410.

57) Yan X, Yu C, Zhou X, Tang J, Zhao D. Highly ordered mesoporous bioactive glasses with superior in vitro boneforming bioactivities. Angew Chem Int Ed 2004; 43: 59805984.

58) Gunawidjaja PN, Lo AYH, Izquierdo-Barba I, García A, Arcos D, Stevensson B, Grins J, Vallet-Regí M, Edén M. Biomimetic apatite mineralization mechanisms of mesoporous bioactive glasses as probed by multinuclear $31 \mathrm{P}, 29 \mathrm{Si}, 23 \mathrm{Na}$ and $13 \mathrm{C}$ Solid-State NMR. J Phys Chem C 2010; 114: 19345-19356.

59) Stanley HR, Hall MB, Clark AE, King CJ 3rd, Hench LL, Berte JJ. Using 45S5 bioglass cones as endosseous ridge maintenance implants to prevent alveolar ridge resorption: a 5-year evaluation. Int J Oral Maxillofac Implants 1997; 12: 95-105.

60) Zhong J, Greenspan DC. Processing and properties of sol-gel bioactive glasses. J Biomed Mater Res 2000; 53: 694-701.

61) Bellucci D, Sola A, Gentile P, Ciardelli G, Cannillo V. Biomimetic coating on bioactive glass-derived scaffolds mimicking bone tissue. J Biomed Mater Res A 2012; 100: 3259-3266.

62) Walker GM. Magnesium and cell cycle control: an update. Magnesium 1986; 5: 9-23.

63) Verberckmoes SC, De Broe ME, D'Haese PC. Dose-dependent effects of strontium on osteoblast function and mineralization. Kidney Int 2003; 64: 534-543.

64) Qiu K, Zhao XJ, Wan CX, Zhao CS, Chen YW. Effect of strontium ions on the growth of ROS17/2.8 cells on porous calcium polyphosphate scaffolds. Biomaterials 2006; 27: 1277-1286.

65) Wu C, Ramaswamy Y, Kwik D, Zreiqat H. The effect of strontium incorporation into $\mathrm{CaSiO} 3$ ceramics on their physical and biological properties. Biomaterials 2007; 28: 3171-3181.

66) Julian B, Pablo C, Humberto P. Sol-gel synthesis and in vitro bioactivity of copper and zinc-doped silicate bioactive glasses and glass-ceramics. Biomed Mater 2015; 10: 025001.

67) Diba M, Tapia F, Boccaccini AR, Strobel LA. Magnesiumcontaining bioactive glasses for biomedical applications. Int J Appl Glass Sci 2012; 3: 221-253.

68) Wang M. Developing bioactive composite materials for tissue replacement. Biomaterials 2003; 24: 2133-2151.

69) Lu L, Peter SJ, D. Lyman M, Lai HL, Leite SM, Tamada JA, Uyama S, Vacanti JP, Robert L, Mikos AG. In vitro and in vivo degradation of porous poly(dl-lactic-co-glycolic acid) 
foams. Biomaterials 2000; 21: 1837-1845.

70) Rowlands AS, Lim SA, Martin D, Cooper-White JJ. Polyurethane/poly(lactic-co-glycolic) acid composite scaffolds fabricated by thermally induced phase separation. Biomaterials 2007; 28: 2109-2121.

71) Liu HL, Liu SJ, Xiao ZL, Chen QY, Yang DW. Excess molar enthalpies of binary mixtures for (tributyl phosphate+methanol/ethanol) at $298.15 \mathrm{~K}$. J Therm Anal Calorim 2006; 85: 541-544.

72) Jin GZ, Kim HW. Nanocomposite bioactive polymeric scaffold promotes adhesion, proliferation and osteogenesis of rat bone marrow stromal cells. Tissue Eng Regen Med 2014; 11: 284290.

73) Kim JJ, Bang SH, El-Fiqi A, Kim HW. Fabrication of nanofibrous macroporous scaffolds of poly(lactic acid) incorporating bioactive glass nanoparticles by campheneassisted phase separation. Mater Chem Phys 2014; 143: 1092-1101.

74) El-Fiqi A, Kim JH, Kim HW. Osteoinductive fibrous scaffolds of biopolymer/mesoporous bioactive glass nanocarriers with excellent bioactivity and long-term delivery of osteogenic drug. ACS Appl Mater Interfaces 2015; 7: 1140-1152.

75) Perez R, Shin SH, Han CM, Kim HW. Bioactive injectables based on calcium phosphates for hard tissues: A recent update. Tissue Eng Regen Med 2015; 12: 143-153.

76) Won JE, Mateos-Timoneda M, Castano O, Planell J, Seo SJ, Lee EJ, Han CM, Kim HW. Fibronectin immobilization on to robotic-dispensed nanobioactive glass/polycaprolactone scaffolds for bone tissue engineering. Biotechnol Lett 2015; 37: 935-942.

77) El-Fiqi A, Kim HW. Mesoporous bioactive nanocarriers in electrospun biopolymer fibrous scaffolds designed for sequential drug delivery. RSC Adv 2014; 4: 4444-4452.

78) Gillam D, Seo H, Bulman J, Newman H. Perceptions of dentine hypersensitivity in a general practice population. $J$ Oral Rehabil 1999; 26: 710-714.

79) Sculean A, Nikolidakis D, Schwarz F. Regeneration of periodontal tissues: combinations of barrier membranes and grafting materials-biological foundation and preclinical evidence: a systematic review. J Clin Periodontol 2008; 35: 106-116.

80) Fernandes JMA, Rego ROCC, Spolidorio LC, Marcantonio RAC, Marcantonio Júnior E, Cirelli JA. Enamel matrix proteins associated with GTR and bioactive glass in the treatment of class III furcation in dogs. Braz Oral Res 2005; 19: $169-175$.

81) Anderegg CR, Alexander DC, Freidman M. A bioactive glass particulate in the treatment of molar furcation invasions. $J$ Periodontol 1999; 70: 384-387.

82) Nevins ML, Camelo M, Nevins M, King CJ, Oringer RJ, Schenk RK, Fiorellini JP. Human histologic evaluation of bioactive ceramic in the treatment of periodontal osseous defects. Int J Periodontics Restorative Dent 2000; 20: 458467.

83) Sculean A, Pietruska M, Schwarz F, Willershausen B, Arweiler NB, Auschill TM. Healing of human intrabony defects following regenerative periodontal therapy with an enamel matrix protein derivative alone or combined with a bioactive glass. J Clin Periodontol 2005; 32: 111-117.

84) Li X, Wang X, Chen H, Jiang P, Dong X, Shi J. Hierarchically porous bioactive glass scaffolds synthesized with a PUF and P123 cotemplated approach. Chem Mater 2007; 19: 43224326.

85) Jung WK, Koo HC, Kim KW, Shin S, Kim SH, Park YH. Antibacterial activity and mechanism of action of the silver ion in Staphylococcus aureus and Escherichia coli. Appl Environ Microbiol 2008; 74: 2171-2178.

86) Esfahani SIR, Tavangarian F, Emadi R. Nanostructured bioactive glass coating on porous hydroxyapatite scaffold for strength enhancement. Mater Lett 2008; 62: 3428-3430.

87) Kim HW, Kim HE, Knowles JC. Production and potential of bioactive glass nanofibers as a next-generation biomaterial. Adv Funct Mater 2006; 16: 1529-1535.

88) Xia W, Zhang D, Chang J. Fabrication and in vitro biomineralization of bioactive glass (BG) nanofibres. Nanotechnology 2007; 18: 135601.

89) Zhang J, Huang J, Xu S, Wang K, Yu S. Effects of $\mathrm{Cu}^{2+}$ and $\mathrm{pH}$ on osteoclastic bone resorption in vitro. Prog Nat Sci 2003; 13: 266-270.

90) Kothapalli CR, Ramamurthi A. Copper nanoparticle cues for biomimetic cellular assembly of crosslinked elastin fibers. Acta Biomater 2009; 5: 541-553.

91) Gérard C, Bordeleau LJ, Barralet J, Doillon CJ. The stimulation of angiogenesis and collagen deposition by copper. Biomaterials 2010; 31: 824-831.

92) Wu C, Zhou Y, Xu M, Han P, Chen L, Chang J, Xiao Y. Copper-containing mesoporous bioactive glass scaffolds with multifunctional properties of angiogenesis capacity, osteostimulation and antibacterial activity. Biomaterials 2013; 34: 422-433.

93) Aina V, Perardi A, Bergandi L, Malavasi G, Menabue L, Morterra C, Ghigo D. Cytotoxicity of zinc-containing bioactive glasses in contact with human osteoblasts. Chem Biol Interact 2007; 167: 207-218.

94) Oudadesse H, Dietrich E, Gal YL, Pellen P, Bureau B, Mostafa AA, Cathelineau G. Apatite forming ability and cytocompatibility of pure and Zn-doped bioactive glasses. Biomed Mater 2011; 6: 035006.

95) Goh YF, Alshemary AZ, Akram M, Abdul Kadir MR, Hussain R. Bioactive glass: an in-vitro comparative study of doping with nanoscale copper and silver particles. Int J Appl Glass Sci 2014; 5: 255-266

96) Bernstein LR. Mechanisms of therapeutic activity for gallium. Pharmacol Rev 1998; 50: 665-682.

97) Franchini M, Lusvardi G, Malavasi G, Menabue L. Galliumcontaining phospho-silicate glasses: Synthesis and in vitro bioactivity. Mater Sci Eng C 2012; 32: 1401-1406.

98) Warheit DB, Reed KL. Nanotoxicology: Environmental, Health and Safety (EHS) considerations for assessing hazards and risks following nanoparticle exposures. Mamm Toxicol 2015: 233-243.

99) Mačković M, Hoppe A, Detsch R, Mohn D, Stark W, Spiecker E, Boccaccini A. Bioactive glass (type 45S5) nanoparticles: in vitro reactivity on nanoscale and biocompatibility. J Nanopart Res 2012; 14: 1-22.

100) Wang S, Gao X, Gong W, Zhang Z, Chen X, Dong Y. Odontogenic differentiation and dentin formation of dental pulp cells under nanobioactive glass induction. Acta Biomater 2014; 10: 2792-2803.

101) Carvalho SM, Oliveira AAR, Jardim CA, Melo CBS, Gomes DA, de Fátima Leite M, Pereira MM. Characterization and induction of cementoblast cell proliferation by bioactive glass nanoparticles. J Tissue Eng Regen Med 2012; 6: 813-821.

102) Erol-Taygun M, Zheng K, Boccaccini AR. Nanoscale bioactive glasses in medical applications. Int J Appl Glass Sci 2013; 4: 136-148.

103) Miyazaki T, Hotta Y, Kunii J, Kuriyama S, Tamaki Y. A review of dental CAD/CAM: current status and future perspectives from 20 years of experience. Dent Mater J 2009; 28: 44-56.

104) van Noort R. The future of dental devices is digital. Dent Mater 2012; 28: 3-12.

105) Azarpazhooh A, Leake JL. Systematic review of the association between respiratory diseases and oral health. J Periodontol 2006; 77: 1465-1482.

106) Yang SY, Piao YZ, Kim SM, Lee YK, Kim KN, Kim KM. Acid neutralizing, mechanical and physical properties of pit and fissure sealants containing melt-derived $45 \mathrm{~S} 5$ bioactive glass. 
Dent Mater 2013; 29: 1228-1235.

107) Wu C, Miron R, Sculean A, Kaskel S, Doert T, Schulze R, Zhang Y. Proliferation, differentiation and gene expression of osteoblasts in boron-containing associated with dexamethasone deliver from mesoporous bioactive glass scaffolds. Biomaterials 2011; 32: 7068-7078.

108) Wu C, Fan W, Zhu Y, Gelinsky M, Chang J, Cuniberti G, Albrecht V, Friis T, Xiao Y. Multifunctional magnetic mesoporous bioactive glass scaffolds with a hierarchical pore structure. Acta Biomater 2011; 7: 3563-3572.

109) Zhu Y, Zhang Y, Wu C, Fang Y, Yang J, Wang S. The effect of zirconium incorporation on the physiochemical and biological properties of mesoporous bioactive glasses scaffolds. Microporous Mesoporous Mater 2011; 143: 311-319.

110) Han $\mathrm{P}$, Wu C, Chang J, Xiao $\mathrm{Y}$. The cementogenic differentiation of periodontal ligament cells via the activation of Wnt/beta-catenin signalling pathway by $\mathrm{Li}+$ ions released from bioactive scaffolds. Biomaterials 2012; 33: 6370-6379.

111) Bellantone M, Williams HD, Hench LL. Broad-spectrum bactericidal activity of $\mathrm{Ag}(2) \mathrm{O}$-doped bioactive glass. Antimicrob Agents Chemother 2002; 46: 1940-1945.

112) El-Kady AM, Ali AF, Rizk RA, Ahmed MM. Synthesis, characterization and microbiological response of silver doped bioactive glass nanoparticles. Ceram Int 2012; 38: 177-188.

113) Melo MA, Guedes SF, Xu HH, Rodrigues LK. Nanotechnologybased restorative materials for dental caries management. Trends Biotechnol 2013; 31: 459-467.

114) Wu C, Zhou Y, Fan W, Han P, Chang J, Yuen J, Zhang M, Xiao Y. Hypoxia-mimicking mesoporous bioactive glass scaffolds with controllable cobalt ion release for bone tissue engineering. Biomaterials 2012; 33: 2076-2085.

115) Gorustovich AA, Roether JA, Boccaccini AR. Effect of bioactive glasses on angiogenesis: A review of in vitro and in vivo evidences. Tissue Eng B Rev 2009; 16: 199-207. 